\title{
Creating New Food Practices : A Case Study on Leftover Lunch Service
}

\section{Laakso, Senja}

2017

Laakso, S 2017 , ' Creating New Food Practices : A Case Study on Leftover Lunch Service '

, Food, Culture, and Society , vol. 20 , no. 4 , pp. 631-650 . https://doi.org/10.1080/15528014.2017.1324655

http://hdl.handle.net/10138/307599

https://doi.org/10.1080/15528014.2017.1324655

acceptedVersion

Downloaded from Helda, University of Helsinki institutional repository.

This is an electronic reprint of the original article.

This reprint may differ from the original in pagination and typographic detail.

Please cite the original version. 


\title{
Creating New Food Practices - A Case Study on Leftover Lunch Service
}

\author{
Senja Laakso, University of Helsinki
}

Department of Environmental Sciences. P.O. Box 65 (Viikinkaari 2a), 00014 University of Helsinki. Tel. +35850 448 0940, e-mail senja.laakso@helsinki.fi, Twitter: @SenjaLaakso, LinkedIn: https://www.linkedin.com/in/senjalaakso

\begin{abstract}
Food wastage is a growing environmental, financial, and social problem: as much as one third of all food is thrown away. Simultaneously, malnutrition is a huge problem globally, and many people even in developed countries are unable to provide for their basic needs. $A$ lot of attention is paid to food waste prevention in the industry, retail sector, and households, whereas the role of food service sector (such as restaurants and canteens providing food in schools, hospitals, and workplaces) has thus far been understudied. In this article, I use a practice theoretical approach to study a leftover lunch service first experimented in Jyväskylä in 2013. I describe how the experiment was organized, how the service has spread around Finland, and how the leftover lunch has become a routine that outlines the course of the day of the diners. I use these findings to illustrate the insights of the service for both environmental and social sustainability, and to situate the service in the field of food waste prevention and food redistribution in Finland.
\end{abstract}

\section{Keywords}

Food, leftover food, food waste, eating, practice theory, experiment 


\section{Introduction}

Food is one of the most critical consumption domains from the standpoint of sustainability (Davies, Devaney, and Pape 2014; Tukker et al. 2010). Of all edible food produced globally, one third is wasted every year, adding more than three billion tons of greenhouse gases to the atmosphere (Gustavsson et al. 2011; Porpino, Parente, and Wansink 2015). At the same time, even in a wealthy Nordic country like Finland, a growing number of people are in need of food (Hanssen et al. 2014). Food waste thus represents a paradox (Cicatiello et al. 2016; Reisch, Eberle, and Lorek 2013): on one hand, there is surplus leading to food waste, and on the other hand, the amount of people unable to provide for their basic needs is growing.

The impacts of modern food production and consumption create "landscapes of unsustainable eating", and ensuring that the needs of eating are met more sustainably in the future requires attention to all phases of the food chain (Davies et al. 2014, 159). Unlike in low-income countries, where food is mainly wasted at the beginning of the chain, the end of the food chain is the center of attention in high-income countries (Gustavsson et al. 2011). Food waste reduction has become a priority among national governments and international organizations alike: in 2015, the EU committed to a 50\% reduction in food waste by $2030^{1}$. Reducing food wastage is also one of the aims towards "climate-friendly food" in Finland (MAF 2014).

Despite the multiple strategies to reduce and prevent food waste at different stages of the food supply chain (c.f. Cicatiello et al. 2016), the actions have mostly focused on informing households and accelerating food redistribution from grocery shops to charity organizations. Before the last couple of years, the role of municipal food service sector canteens and restaurants providing meals in day-care centers, schools, hospitals, elderly service centers, and workplaces - has received less attention, despite its major impact on Finnish food production and consumption: one third of the population use these services daily (Hanssen et al. 2014). About 20\% of food handled and prepared in these restaurants is wasted annually (Silvennoinen et al. 2012), the share being similar to that of other countries (Betz et al. 2015). Food service sector is thus an area where sustainability interventions can lead to significant positive impacts (Goggins and Rau 2015).

The City of Jyväskylä was the first municipality in Finland conducting an experiment that aimed at reducing the amount of food waste due to serving losses in schools. After a lunch hour for school children, retired and unemployed people could come and have a "leftover lunch." This both reduces the amount of food waste - and environmental impacts of food waste - and provides an opportunity for a social meal for diners. Since 2013, when the experiment first took place, the leftover lunch service has spread all over Finland. However, the service has been analyzed mainly from the perspective of environmental and financial impacts (c.f. Mattinen et al. 2014). As in many other cases of experiments, and food service industry in general (Betz et al. 2015), the participant perspective is studied to a lesser extent.

\footnotetext{
${ }^{1}$ http://europa.eu/rapid/press-release_IP-15-6203 en.htm (accessed 17.5.2016)
} 
Videira et al. $(2013,2)$ suggest that sustainable food consumption means "obtaining and consuming sufficient amounts of nutritious and safe food to stay healthy and active, as well as dealing responsibly with issues of resources, emissions, and waste." This article shows how the leftover lunch service can help to meet these conditions. I use a practice theoretical approach to analyze the service from two different perspectives. First, I describe the broadening of the service from a small-scale experiment to a practice entity complementing food waste prevention and food redistribution practices in many Finnish municipalities. After that, I explain how participating in the leftover lunch has become a routine that outlines the course of the day of the diners performing it. These findings illustrate the outcomes of the service to both environmental and social sustainability.

The paper proceeds as follows: Section 2 introduces the theoretical background of the study. Section 3 presents the how the leftover lunch service has been organized and how it has become a recognizable practice entity. The remainder sections focus on performances of the practice: Section 4 presents materials and methods, and Section 5 the results of the study. Section 6 discusses the results from the perspective of both organizers and users of the service. Section 7 is the concluding section of the paper.

\section{Theoretical background - A Practice Approach to Food Consumption}

Practices - routinized behavior guided by "shared understandings, know-how and standards of the practice, the internal differentiation of roles and positions within it, and the consequences for people of being positioned relative to others when participating" (Warde et al. 2007, 364) - are widely studied in fields of food (Dubuisson-Quellier and Gojard 2016; Halkier 2009; Maguire 2016), eating (Warde 2016), food waste (Evans 2012; Watson and Meah 2012), and experiments disrupting food consumption (Devaney and Davies 2016), to name some.

Practices can be understood both as performances and as entities (Schatzki 2002). As $a$ performance, eating is to a high degree habitual and "inconspicuous" (Shove and Warde 2002; van't Riet et al. 2011). Food practices are often situated in intersections of multiple practices - eating, for instance, requires performances of producing, distributing, purchasing, preparing, and cooking the food (Devaney and Davies 2016; Halkier and Jensen 2011; Kjærnes et al. 2001; Reckwitz 2002). Patterns of eating, as well as of many other everyday practices, have a "uniform rate of recurrence" (Southerton 2013, 348) - eating is done routinely from one day to another, at the same way, at the same time, at the same place. Practices as entities, such as having lunch, are reproduced by these day-to-day performances of the practice, and thus link these individual acts to wider systems of provisioning (Devaney and Davies 2016). 
Although a performance "presupposes a practice," it is in the multitude of performances that individuals "carry that practice forward, expressing, affirming, reproducing and transforming it" (Warde 2016, 40). Even if performances are unique, members of social groups exhibit significant features of behavior in a similar manner (ibid.). Practices are thus, by nature, social. The companionship - who is present - matters greatly for the practices of eating. Sociality and commensality affect the ideas about proper eating, care, and convenience, but also on rules and manners of eating (Fiese, Foley, and Spagnola 2006; Fischler 2011; Paddock 2015). Meal patterns constitute a strong example of collective behavior and exemplify the normative force of shared sequencing of eating events (c.f. Holm et al. 2012; Rotenberg 1981; Yates and Warde forthcoming). Although practices as entities are recognizable, describable, and shaped by numerous socio-cultural and material elements, it is still by 'doing' a practice that it becomes meaningful (Southerton 2013).

Being context dependent, practices are always adjusted to particular situations, and the location has gained importance as part of the definition of eating events: getting the appropriate people together, at the proper time for a particular type of meal is "the practical skill" of arranging a meal event (Warde 2016, 46, 63). Practices also become institutionalized (Holm et al. 2012), referring to both organizations such as school canteens, and to ways of doing things, like distributing food. These institutions attempt to coordinate and regulate performances by prescribing rules, prohibiting or discouraging particular forms of behavior, and defining standards of performance, for instance (Warde 2016, 45). Intermediaries (such as authorities and media) affect the coordination and regulation of eating, the role of controversy in popular judgments, and justifications of behaviors (Warde 2016). Examples of these can be seen in discussion on edibility and safety of food (c.f. Blichfeldt, Mikkelsen, and Gram 2015). In other words, food practices are "diverse and nuanced individual and collective negotiations of institutional, spatial and cultural impediments to achieving desired food outcomes" (Maguire 2016, 12).

To conclude, practices constitute of complex dynamics between elements and other practices. Eating is simultaneously personal and collective, and is shaped by a combination of cultural and social norms, contexts, and habits, rules and regulations, modes of provision, and technologies and infrastructures (Devaney and Davies 2016; Delormier, Frohlich, and Potvin 2009; Paddock 2015). As Warde (2016, 63) notes: "A specific social and cultural meaning is attached to the performance of eating occasions from the permutation and juxtaposition of time, place and company." The analysis of eating practices and elements constituting the practice - the foods consumed, bodily processes and social arrangements (ibid.), thus resembles the concept of eating system of Mäkelä et al. (1999), which frames the general dimensions of the meal: eating pattern and rhythm, the format of the meal, and social organization of eating. Examination of the "ways in which these elements are orchestrated in the myriad quotidian performances of food consumption" provides the basis for describing and analyzing eating as a social practice (Warde 2016, 150). 


\section{Leftover Lunch Service in Finland - From Experiment to Entity}

Communal food services are an integral part of Finnish food culture, as they provide up to half of meals consumed outside the home (Silvennoinen et al. 2012). Having a hot lunch - a meal especially common, and commensal, in Finland - may even be seen as participating in the "national culture" (Kahma et al. 2014; Kristensen and Holm 2006). In Finland, as well as in the neighboring countries Sweden and Estonia, for instance, children are provided a free lunch every school day. A basic school meal consists of a warm main course, vegetables, bread, table spread, and a drink, and the school catering is designed to follow the dietary guidelines issued by the National Nutrition Council'2. Previously meals were cooked on site, and it was easier to control the amount of food waste on a daily basis, as kitchens were able to react on notices of student absences. Many schools have, however, shifted to ordering meals from municipal catering companies, which makes estimating the daily consumption more difficult. This, in combination with strict rules on how heated food from serving dishes may be further processed, often leads to surplus of food - which accounts for $60 \%$ of the food waste in Finnish schools (Silvennoinen et al. 2012).

In the field of food waste prevention, donations and redistribution have garnered growing interest, as means for both tackling the environmental impacts of food waste, and steering food surplus to those who are in need (Girotto, Alibardi, and Cossu 2015). Despite long tradition of food redistribution in Finland, mostly by more than 400 religious parishes, organizations of unemployed and non-governmental organizations redistributing food from wholesalers and retail shops, it is still loosely organised (Hanssen et al. 2014). The main barriers for efficient redistribution are related to systems for quality assurance, infrastructure, legislative frameworks, as well as financing (Hanssen et al. 2016). Simultaneously, as much as 50,000 meals' worth of food is being thrown away annually in schools and service centers in a city the size of Jyväskylä3. One way of solving these kinds of contradictions are experiments that introduce novel ways of doing things and establish niches for testing these (c.f. Laakso, Berg and Annala forthcoming).

The city of Jyväskylä in Finland has acted as an arena of a variety of experiments: in 20132015 the Finnish Innovation Fund Sitra and the City of Jyväskylä conducted a joint project that promoted "wise use of natural resources and creating the preconditions for sustainable well-being" 4 . As part of the project, experiments varying from encouraging behavioral change to changing ways of organizing municipal services, were implemented (c.f. Berg, Hildén, and Lahti 2014; Laakso forthcoming; Laakso and Lettenmeier 2016).

The leftover lunch service was one of these experiments, and it was conducted on the basis of an idea of a school canteen worker. The service aimed at minimizing serving losses (i.e. food left in serving dishes after the children's lunch) in schools and thus reducing the environmental impacts of food waste. Every day, after the students' lunch hour, canteen

\footnotetext{
${ }^{2}$ http://www.ravitsemusneuvottelukunta.fi/portal/en/nutrition+recommendations/ (accessed 17.5.2016)

${ }^{3} \mathrm{http}: / / \mathrm{www}$. sitra.fi/en/news/resource-wisdom/leftover-lunch-trend-spreading-around-finland (accessed 17.5.2016)

${ }^{4}$ http://www.sitra.fi/en/ecology/resource-wisdom (accessed 17.5.2016)
} 
workers hang either a red note, stating that there is no food left, or a green note, welcoming people inside for a lunch, to the canteen door. If there is food left in serving dishes, people can come for a lunch in the canteen. Canteen workers themselves are responsible for organizing the service.

The service was first experimented for two weeks at one service center for elderly people and one school. After the two-week experiment, canteen workers at the service center concluded that as the lunch that they normally provided was not free for the customers, the leftover lunch opportunity just made the customers shift their lunch hour later, so that they could pay less for the meal as it had become a "leftover lunch" (Mattinen, Antikainen, and Salo 2014). As there were no similar problems at the school, the leftover lunch continued and soon spread to two other schools.

Since the beginning of the experiment in 2013, the service has gained a lot of media attention, which has accelerated the spread of the new practice to schools in other municipalities. In 2013, members of the Parliament presented a written question to the Government about the promotion of the leftover lunch service in Finland. In 2014, Sitra published guidelines for organizing the service for municipal workers, to facilitate further broadening of the practice. Despite some differences between municipalities, the main principles of the service remain the same. The public service providers cannot profit from the service. In Jyväskylä, the leftover lunch costs 1.50 euros, which covers the cost of bread, spread, and a drink - the meal itself is free. The service is targeted for elderly, unemployed, and other non-working people, although the income of diners is not controlled and thus everyone can come for a lunch. The main aim is still to minimize food surplus in the first place, so there is not always leftover food left.

More than thirty municipalities around Finland now service leftover lunch daily. The service has also been made permanent in the three schools in Jyväskylä, and it will be implemented in rest of the schools in 2016. More than 7,000 meals, 6-30 daily, were served in 2014 in these three schools, mostly to elderly people. It can thus be said that the practice of serving leftover lunch has become an entity, constituting of common understandings, rules, infrastructures, and recognizable sequences of actions, and being guided by standards for successfully organizing the service.

\section{Materials and Methods}

The study was conducted in Jyväskylä in November 2015. I visited all three schools providing leftover lunch and interviewed a cook in charge in each school, as well as the service manager of the caterer, before my visit. The interviews, as well as newspaper articles and other material available on the service, served as background information for the study. 
I had lunch at each school. During the meal, I discussed with the diners and observed how the lunch event was organized. I also asked the diners whether I could interview them later. Of almost sixty people attending lunch, twenty-four (twelve women and twelve men) agreed for an interview. Thirteen of them lived alone and eight were couples (both parties were participating in an interview in three cases). The age of the informants varied between 52 and 83 years. Two informants were unemployed and the others were retired. The income of the informants varied from 400 to 1,600 euros per person per month after housing expenses. Most of the interviews occurred in informants' homes. Six interviews were done by phone. The semi-structured interviews covered the following themes: background information of the informant, organization of a normal day, participating in the leftover lunch, eating and activities related to it in general, and environmental aspects of food waste.

I coded the transcribed interviews on the basis of the abovementioned themes. The focus of the analysis was on the role that the leftover lunch had in informants' everyday living. In addition, I categorized the informants on the basis of their income, size of the household, distance from home to school and the main reasons for, and regularity of, participating in the lunch. The notes from the lunch events supported the analysis to cover both the practical activity (doings) and its representations (sayings) (Warde 2005, 134). The following presentation of the results is based on the findings of this analysis on the major similarities among the informants on how they experienced the leftover lunch service.

\section{Results}

This section describes how the leftover lunch has been incorporated in the informants' everyday living: what is the role of the leftover lunch in daily structure and rhythm? How significant is the lunch as a meal, and as a social occasion?

\section{1 "It has become a daily habit"}

Twenty-two informants had been going to the leftover lunch for more than six months. Twelve of them went there daily or at least four times in a week, seven on most weekdays, and five more irregularly. Most informants told that they cooked something at home on weekends and holidays. Some bought ready meals from the grocery shop "to manage through the weekend." When the informants cooked something, they often made food for several days. If they still had food left from the weekend on Monday, they put it in freezer rather than skipped the school lunch. This way they were also prepared for those days they could not go to the school or there was no food left.

"I go there regularly; usually I don't skip the lunch. If I have some food left from the weekend I put it in the freezer, so that sometimes, if I have some plans and I cannot make 
it [to the school], I can have something from the freezer, or eat it on the next weekend." (Irma5)

The school lunch menu is published weekly in a local newspaper and most of the informants told that they looked at the menu beforehand daily and weekly - some even printed the menu from Internet for several weeks in advance. This did not, however, effect on whether they went to have a lunch or not: it was mostly just for interest and fun. Some of the informants, however, also used the menus to estimate whether there was food left or not: if the day's lunch was something that the children liked, there was probably less food left. On these days, some of the informants (especially couples) rather stayed home and cooked something themselves.

"I cut the weekly menu from the newspaper. Then I sometimes check the menu from the Internet. But it does not effect on whether I go there or not." (Riitta)

The canteens had entrances both from the outside and from the classrooms. Diners coming to the leftover lunch had to wait outside for the children's lunch hour to end - they were not allowed to wait inside to avoid disturbances in school activities. After the canteen worker had brought the green note on the door, the diners went in, took food on their plates, paid for the meal and sat down to eat. Despite people chatting with others quite freely outside, there were certain places where the diners sat down at the canteen. Most of the diners sat in groups of four to six, and some couples and men were by themselves.

"We don't have any personalized seats. However, it has become like that, everyone is sitting where they are used to sit. At first, I used to sit at the back of the canteen, but it did not feel cozy, so I moved by the door. I like sitting there, it is easy to leave from there, and there are no too many people who want to sit round that table. And now there is a group of men sitting at the back, where I used to." (Toini)

The eating itself was a quick event: the canteen workers had expressed a wish for diners not to linger over their meals, as they had to prepare the canteen for the afternoon snack of the children. Therefore, the diners left right after they had finished their meals and the dining itself did not last more than 20 minutes. Most of the informants told that this was long enough time for them to finish their meal at leisure.

"They never say anything, but I can read between the lines that they wish us to be fast, so that they can start preparing the next meal." (Tapani)

The informants planned their days in a way that they had time to go for a lunch, and their daily activities occurred before and after the lunch. Almost all informants lived within a walking-distance (less than one kilometer) from the school and other daily activities, such as shops and hobbies, so they mostly walked or bicycled to the school. As they were already

\footnotetext{
${ }^{5}$ The informants have been given pseudonyms in order to preserve their anonymity.
} 
on the move, they often went to run their other errands after the lunch. Some of the informants combined the lunch trip with a longer walk to get their daily exercise.

"It gives a kind of organization for the day: I go for a walk and straight after that to the school for a lunch. So I manage to do exercise every day.” (Riitta)

"It is very important service, for old people, and for widows and those who live alone. It interrupts the day at noon, every day, you have to go there; it brings a backbone to everyday living. In this house, as well, people can still wear their nightclothes in the middle of the day. I think that there has to be a reason for people to dress themselves, some program in the day that keeps you moving. Just like when you are working." (Mirja)

When there was no food left (which had happened only eight times in the past six months in three schools altogether), it was signaled by the red note on the canteen door. Nine informants occasionally went to the other schools or nearby cafeterias for lunch. The rest told that if there was no food left at the school, they went home and had something from the freezer, or grabbed something from a shop on their way home, as the distance to the other schools was too long or they could not afford to have lunch elsewhere.

"I have never gone to other schools, just this one next to home. If I cannot go there or there is no food left, I cook something at home. I don't bother going as far as to the other schools for a lunch.” (Anneli)

To sum up, going to the leftover lunch had become a daily habit for most of the informants and they routinely repeated it every weekday, just like working people are repeating their lunch routines. Unlike in previous studies, in which meals patterns were formed on the basis of social schemes, and rhythms at work and in leisure time, for instance (Kristensen and Holm 2006), the leftover lunch was a practice on the basis of which other meals and activities were planned. As Devaney and Davies (2016) also note in their study, performing a new practice required that the diners connected multiple interdependent practices of eating, such as acquisition, storage, and preparation, in a new way. Leftover lunch demanded preparations and techniques in a way that the informants had portions of food in freezer for the situations in which there was no food left at the school, and they organized their other daily routines around the school lunch - both spatially and temporally (c.f. Southerton 2013).

\section{2 “At least something wholesome"}

For twenty informants, the leftover lunch was the main meal of the day. Many of the informants mentioned that their eating routines had changed after their children moved out, from two daily hot meals to one. No one regularly ate another hot meal in the evening, but the rest of their daily nutrition consisted of something light, such as coffee and sandwiches. The informants either did not want to cook every day, as they felt that cooking for just one 
person was frustrating, or they "did not know how to" cook only small amounts of food, as they had used to cook for the whole family. For some informants, going to the school for a lunch was also a way to make sure that they actually ate a hot meal at least once a day.

"I go [to the school] to eat because I live by myself, so I don't usually cook. Therefore, when I go there I really do eat a hot meal once a day. Eating is a bit this and that, when you live alone." (Jaakko)

"I live alone, and it feels very frustrating to cook as I have to make big portions, and then I need to eat it for days, or to freeze it, and some of it goes to waste. There is no point in cooking small portions. It is quite expensive, too. In this sense, [the lunch] is a very good system."(Eila)

As schools mostly serve traditional Finnish foods, the familiar courses were the same that the informants would have made themselves at home. Many of the informants mentioned the variety and diversity of meals: they had different food every day, and the salads and breads were fresh. Some of the informants having health problems, such as high cholesterol, actually felt healthier. Many of them told that they could not cook as diverse and wholesome food at home.

"It is tasty food. Once I told to my son that I went [to the school] to eat meat sauce. He asked if I really went there to eat such a basic food. I told him that I really did, I'm not going to start cooking for myself only. I don't mind if it is ordinary, what does it matter? I like it and I have told all skeptics that not many people have as good meals at home on weekdays as those at the school are." (Irma)

"I have diabetes, so it is really good for me to have the lunch at the school daily. If it is good enough for the children, it has to keep an old man like me moving as well." (Jaakko)

The affordability of the lunch was important: most of the informants considered themselves as low-income and three described themselves as poor. Some mentioned saving money, not just in a way that they had to spend less for groceries, but also by saving electricity, as they did not have to cook or wash dishes. However, most of the informants were not ready to pay much more for the lunch, as it was, after all, "going to waste anyway." In addition, many of the informants calculated that if the lunch was more expensive, it would be cheaper to cook by themselves.

"I might be able to use the same amount of money by cooking myself, it is not expensive to cook, but anyway, 1.50 euros is not much. -- I never go [to other places]. They are too expensive for me. -- I just put aside the 31.50 in the beginning of the month and that's enough for the whole month!" (Anneli)

"This leftover lunch service has been really good, because I can't always afford to buy food. -- At the end of the month, I sometimes realize that I don't have any money left, and I have 
to think what I can afford to eat. I cook porridge, this kind of food that I can get on the cheap."(Liisa)

Only a few of the informants mentioned that they had received food aid from charity organizations before. Most of the informants did not consider school lunch as food aid either. Seven informants mentioned the shame when they were thinking about reasons for other people not going to lunches, and only one of them said that she had sometimes felt ashamed for queuing to leftover lunch. On the contrary, all the informants highlighted the importance of preventing food waste as one of the main reasons for having the lunch.

"For some people there seems to be a threshold, and they feel that they would be inferior to others, or poor, like one lady said. I don't feel that I'm poor; I go there for the food. I mean, they cook the food and I have an opportunity to eat it, I feel bad to watch how the food is wasted. It is good, nutritious food." (Taimi)

Preventing food waste was not as much an environmental issue as it was a moral and ethical issue: the informants were taught to clean their plates when they were children, as there had often been food shortages, and the idea of throwing good food out simply "felt bad." Seeing food waste from this perspective was also due to the age of the informants: for many of the informants the concept of "environment" was unfamiliar. Some informants told that they tried to live environmentally friendly and avoid unnecessary driving, for instance, and that environmental aspects were one more reason for participating in the leftover lunch. These informants were, however, a minority.

"I don't waste food, I'm really strict about it. -- Because, if we think about the world, there are so many people starving. So I think it should be a moral obligation, to take care of not wasting anything." (Mirja)

To sum up, the meal had many meanings. It was nutritionally and financially important for many informants: it provided a wholesome meal for people who did not know how to, did not bother to, or could not afford to cook by themselves. A gender division (e.g. Bugge and Almås 2006; Warde et al. 2007) could be seen in the interviews, as well: whereas elderly men did not know how to cook, elderly women, to the contrary, did not have anyone to cook for. The distinction between edible food and food waste (Blichfeldt, Mikkelsen, and Gram 2015) that the informants had to make, had made the informants to reflect their thoughts about the service. The concepts of a "proper meal" (Kjærnes et al. 2001) or "proper eating" (Bugge and Almås 2006) were highlighted in many interviews. As food was going to be thrown away if not eaten, it was a "responsibility" for some to eat it (c.f. Evans 2012; Johnston, Szabo, and Rodney 2011; Nielsen and Holm 2016; Watson and Meah 2012).

\section{3 "We have such a good time"}


The social aspects of the leftover lunch, such as seeing other people, were mentioned by seventeen of the informants - both singles and couples. Most of the informants had children and they saw them regularly. These occasions did not, however, include eating together, but having family dinners was mostly related to birthdays and holidays. Only four of the informants sometimes invited their children, and four informants told that their children invited them, for a dinner outside the holidays. Two informants occasionally saw their friends over a dinner. Five of the informants described themselves as lonely, and did not have anyone to visit or invite over.

For most informants the lunch had thus become a daily social event: the diners knew each other and they had an "unspoken rule" of reporting to the others whether they were not going to come for a lunch the next day. Many came already before the end of children's lunch hour to wait outside the canteen: for them, the time before lunch was an opportunity to chat with others.

"It is important as a social event, for pensioners like myself: I live alone, and I am quite lonely. -- We come there often twenty minutes before and we have a loud social chatter going on, every day, catching up. We have quite a close social community, actually, and we all know each other. There might be some people who are more unsociable, some older men, who rather eat by themselves. But we always chat." (Anneli)

"Yes it is important [socially]. We have become almost like a team. There is always around ten of us, today there were two missing, they are on a holiday. If someone doesn't show up and hasn't told anything beforehand, we are wondering what has happened. -- I have gone to the other school once or twice. It is all right, but people there are not familiar. I have become homely to the school." (Martti)

Although many of the informants mentioned the warm atmosphere among the diners at the school, only some of them had actually made new friends. The diners at the school were mostly "nodding acquaintances": they were greeted on the streets or shops if they were bumped into, but were not purposefully met outside the school.

"I say hello to everyone I have met at the school if we bump into each other on the street, even if I don't really know them." (Reijo)

Only four informants said that the sociality of the lunch was not that important. For them, however, the lunch was not as much of meeting other people as of not eating alone. Even if these informants came to the school "only to eat, not to meet other people" and did not much talk to anyone, the lunch was still an opportunity to feel the presence of other people. The school lunch was a mean for avoiding loneliness.

"It is, like, a social contact. I get to see people - it makes food tastier. When I eat here at home, alone, I sometimes don't even have an appetite, and I think 'is this worth it?' I think that I don't even bother boiling the potatoes just for myself." (Liisa) 
Sociality was also an important factor in hearing about the service, or recruiting new diners. Most of the informants had heard about the service from someone else. Even if some had read news about the experiment from the local newspaper, they still talked about the lunch with someone who had gone there previously, to find out more about the service.

"A man from the neighbor told me [about the service], he was just coming from the school lunch, and he told me to go there. I hadn't heard about it before, he told me that the doors at the back yard open at quarter past twelve and that I can go and have a lunch there." (Toini)

"I read from the local newspaper that they are experimenting this kind of thing. Then, I asked someone in the neighborhood whether she had tested it, and how is it working. She told that we can go for a lunch as well, as it is meant for pensioners and unemployed people."(Sirpa)

Almost all informants had been talking about the service with their neighbors or other acquaintances, but they did not see it necessary to actively promote the service as they also recognized that there would be no enough food for large crowds. Sometimes the lack of food indeed caused some bad feelings and disappointment among the diners, although they tried to share what was left and some of the informants - especially couples - told that in these occasions they were the "volunteers" to go home for a lunch, as they recognized that others needed the service more.

"There are always the same people who are there first; they come there half an hour in advance to wait and are the first to be let in. Always the same people get food, and others are left without if there is not enough." (Liisa)

To sum up, the sociality and commensality (e.g. Fischler 2011; Kahma et al. 2014; Sobal and Nelson 2003) of the leftover lunch event was highly appreciated as, unlike studies reviewed by Polivy \& Pliner (2015) indicate, most of the daily meals were eaten alone. Even if the school was not primarily a place to meet other people, it was a chance to avoid a solitary meal: as previous studies (Kjærnes et al. 2001; Warde 1999) have shown, eating alone is rarely the preferred option for most people - even not considered to be a "meal at all" (Pliner and Bell 2009, 169). The diners had formed a community around the leftover lunch, and this also distinguishes the leftover lunch from many other forms of food redistribution: instead of negative meanings associated to queuing in bread lines, for instance, some informants voluntarily left home early to catch up with others at the school yard. Despite some bad feelings related to occasional shortage of food, the presence and familiarity of other people (Giacoman 2016; Lee 2015; Nielsen and Holm 2016) was important.

\section{Discussion}


This section draws from findings presented in Section 5 and discusses about the results both from the perspective of everyday routines of the diners and in terms of context and framing of the leftover lunch service.

Participating in the leftover lunch had become a routine for many diners - it provided a daily reason for leaving home and having some exercise, and a wholesome hot meal with other people. It was both a personal and a collective practice, shaped by norms and rules of performing the practice, meanings of proper, commensal eating, and competences of organizing everyday living on the prerequisite of being at a certain place at a certain time (Devaney and Davies 2016; Delormier, Frohlich, and Potvin 2009; Paddock 2015; Warde 2016). After the retirement or unemployment, a person easily drops out of the familiar rhythms (Jonsson, Borell, and Sadlo 2000), and provision of a regular lunch enables these people to maintain a structure in their everyday living. In addition, regular and commensal eating practices are perceived to enhance the quality of life and health of individuals by providing predictability and stability (Holm, Lund, and Niva 2015; Jastran et al. 2009). Gathering for a lunch at the school and establishing "commensal relationships (Sobal and Nelson 2003) could be compared to eating a family dinner at home that is still an important everyday ritual in most people's lives (Bugge and Almås 2006; Fiese, Foley, and Spagnola 2006) but not an option for many elderly or lonely people.

The school as a space for having lunch had many advantages: first, instead of just selling food to go, it provided a space for eating together - although not everyone considered the social aspect important, the lunch was still an opportunity to avoid eating alone (Lee 2015). Second, as the diners mostly came from within one-kilometer radius from the school, it was easier to distribute the information about the service by "the word on the street" in the neighborhood. Participating neighbors acted as peers validating the service, as they provided references and hence lowered the threshold of participating in the lunch (Dubuisson-Quellier and Gojard 2016). Third, schools are institutes providing the infrastructure, facilities, and canteen workers' professionalism for food provision. Dense school network enables also elderly diners with reduced mobility to participate in the lunch, increasing their independence. Fourth, the different diner groups (such as school children and elderly or unemployed people) made organizing leftover lunch possible, as there was no risk of the paying customers to switch to leftover lunches for canteens or risk of facing the judgment of other adults for the diners.

The leftover lunch service was originally experimented as a way to reduce food waste, and hence cut down the GHG emissions at the local level. This framing of the service as an environmental act, rather than food aid for low-income people (although they were the target groups) was important - even if most diners did not even see the service as a matter of environmental sustainability. This was due to the social acceptability of participating in the lunch. Food waste prevention agenda attracted also some higher-income diners for lunch. If the service were framed as food aid, the threshold of participating might have been higher (Hanssen et al. 2016). The framing also made the role of canteen workers easier, as 
they did not have to act as gatekeepers, estimating who needed the service most, but their main task was to minimize the amount of food waste.

\section{Conclusions}

As this article has shown, the leftover lunch has become a nationally recognized way of reducing edible food waste in schools. This is due to the positive media attention, institutions providing the facilities, and active municipal workers making the initiatives for organizing the service at the local level. Practice theoretical perspective for analyzing the service provided insights on the dynamics behind the development and maintenance of the new practice. The ways the leftover lunch service was organized - how the meal was prepared, where it was served and how the service was framed - scripted the ways in which diners participated in the lunch and talked about it. However, the people participating in the lunch, or carrying the practice, were also important in reproducing the practice and recruiting new practitioners. Maintaining the practice happens in a constant dynamics between all these elements.

Situating the service in the field of food waste prevention and food redistribution in Finland is not, however, straightforward. In terms of the main aim of the service - minimizing the amount of edible food waste in schools - the service was successful. Although the tradition of serving school lunch varies by nations, the service could have potential outside Finland, as studies have recognized that food surplus in schools and other (municipal) food services is a challenge in other countries, as well (Betz et al. 2015; Engström and Carlsson-Kanyama 2004).

The service does complement the established food redistribution practices in Finland, although it is not systematically seen as such. Problems are related to, for instance, the contradiction between food waste prevention targets and social support the service provides: as the main aim is to minimize serving losses in the first place, the leftover lunch service cannot be seen as a stable form of food aid. As social networks in the neighborhood are important for learning about the service, the most disadvantaged people might not even know about the service. Thus, although the service has many social and structural benefits, it should not be seen primarily as food aid.

Future studies could focus on leftover lunch service and its users in other municipalities. It would also be important to experiment similar services in other public food services and outside Finland, and to study the role of these new services in relation to existing food redistribution organizations and institutions to find the right position for the service. The role of framing in sustainability experiments is also interesting, and could be further studied.

Lastly, the prerequisite of the need for these kinds of services in the first place could be seen both environmentally and socially unsustainable, as there should be no edible food waste to 
distribute nor people suffering from food insecurity. However, as long as these both exist, the leftover lunch service has a wider potential in tackling the issue of food waste, while making use of the existing facilities in bringing people together for a lunch.

\section{Acknowledgements}

The author would like to thank the anonymous reviewers for their in-depth comments and constructive suggestions, which helped to improve the quality of the article considerably.

\section{Author biography}

Senja Laakso, MSci, is a doctoral researcher at the University of Helsinki, Department of Environmental Sciences. Her research focuses on local sustainability experimentation.

\section{ORCID}

http://orcid.org/oooo-0oo2-9156-4252

\section{Disclosure statement}

No potential conflict of interest was reported by the author.

\section{Funding}

This work was supported by the University of Helsinki doctoral programme in interdisciplinary environmental sciences (DENVI). 


\section{References}

Berg, Annukka, Mikael Hildén, and Kirsi Lahti. 2014. "Kohti Kokeilukulttuuria.” Selvityksiä 77. Helsinki.

Betz, Alexandra, Jürg Buchli, Christine Göbel, and Claudia Müller. 2015. "Food Waste in the Swiss Food Service Industry - Magnitude and Potential for Reduction." Waste Management 35: 218-226. doi:10.1016/j.wasman.2014.09.015.

Blichfeldt, Bodil Stilling, Marie Mikkelsen, and Malene Gram. 2015. "When It Stops Being Food: The Edibility, Ideology, Procrastination, Objectification and Internalization of Household Food Waste." Food, Culture \& Society 18 (1): 89-105. doi:10.2752/175174415X14101814953963.

Bugge, Annchen Bahr, and Reidar Almås. 2006. "Domestic Dinner: Representations and Practices of a Proper Meal among Young Suburban Mothers." Journal of Consumer Culture 6 (2): 203-228. doi:10.1177/1469540506064744.

Cicatiello, Clara, Silvio Franco, Barbara Pancino, and Emanuele Blasi. 2016. "The Value of Food Waste: An Exploratory Study on Retailing." Journal of Retailing and Consumer Services 30: 96-104. doi:10.1016/j.jretconser.2016.01.004.

Davies, Anna R., Laura Devaney, and Jessica Pape. 2014. "Eating." In Challenging Consumption. Pathways to a More Sustainable Future, edited by Anna R. Davies, Frances Fahy, and Henrike Rau, 158-181. Oxon: Routledge.

Delormier, Treena, Katherine L. Frohlich, and Louise Potvin. 2009. "Food and Eating as Social Practice - Understanding Eating Patterns as Social Phenomena and Implications for Public Health." Sociology of Health and Illness 31 (2): 215-228. doi:10.1111/j.14679566.2008.01128.x.

Devaney, Laura, and Anna R. Davies. 2016. "Disrupting Household Food Consumption through Experimental HomeLabs: Outcomes, Connections, Contexts." Journal of Consumer Culture. doi:10.1177/1469540516631153.

Dubuisson-Quellier, Sophie, and Séverine Gojard. 2016. "Why Are Food Practices Not (More) Environmentally Friendly in France? The Role of Collective Standards and Symbolic Boundaries in Food Practices." Environmental Policy and Governance 26 (2): 89-100. doi:10.1002/eet.1703.

Engström, Rebecka, and Annika Carlsson-Kanyama. 2004. "Food Losses in Food Service Institutions Examples from Sweden." Food Policy 29 (3): 203-213. doi:10.1016/j.foodpol.2004.03.004.

Evans, David. 2012. "Beyond the Throwaway Society: Ordinary Domestic Practice and a Sociological Approach to Household Food Waste." Sociology 46 (1): 41-56. doi:10.1177/0038038511416150.

Fiese, Barbara H., Kimberly P. Foley, and Mary Spagnola. 2006. "Routine and Ritual Elements in Family Mealtimes: Contexts for Child Well-Being and Family Identity." In 
Family Mealtime as a Context of Development and Socialization, edited by R. W. Larson, A. R. Wiley, and K. R. Branscomb, 67-89. San Francisco, CA: Jossey-Bass. doi:10.1002/cad. Fischler, Claude. 2011. "Commensality, Society and Culture." Social Science Information 50 (3-4): 528-548. doi:10.1177/0539018411413963.

Giacoman, Claudia. 2016. "The Dimensions and Role of Commensality: A Theoretical Model Drawn from the Significance of Communal Eating among Adults in Santiago, Chile." Appetite 107: 460-70. doi:10.1016/j.appet.2016.08.116.

Girotto, Francesca, Luca Alibardi, and Raffaello Cossu. 2015. "Food Waste Generation and Industrial Uses: A Review.” Waste Management 45: 32-41. doi:10.1016/j.wasman.2015.06.008.

Goggins, Gary, and Henrike Rau. 2015. "Beyond Calorie Counting: Assessing the Sustainability of Food Provided for Public Consumption.” Journal of Cleaner Production 112: 257-266. doi:10.1016/j.jclepro.2015.06.035.

Gustavsson, Jenny, Christel Cederberg, Ulf Sonesson, Robert van Otterdijk, and Alexandre Meybeck. 2011. "Global Food Losses and Food Waste: Extent, Causes and Prevention." Rome.

Halkier, Bente. 2009. "A Practice Theoretical Perspective on Everyday Dealings with Environmental Challenges of Food Consumption." Anthropology of Food S5: 1-16. http://aof.revues.org/6405.

Halkier, Bente, and Iben Jensen. 2011. "Methodological Challenges in Using Practice Theory in Consumption Research. Examples from a Study on Handling Nutritional Contestations of Food Consumption." Journal of Consumer Culture 11 (1): 101-123. doi:10.1177/1469540510391365.

Hanssen, Ole Jørgen, Per Ekegren, Irmelin Gram-Hanssen, Pirjo Korpela, Nanna LangevadClifforth, Kristin Skov-Olsen, Kirsi Silvennoinen, Malin Stare, Åsa Stenmarck, and Erik Svanes. 2014. "Food Redistribution in the Nordic Region. Experiences and Results from a Pilot Study.” TemaNord 562. Copenhagen. doi:10.6027/TN2014-562.

Hanssen, Ole Jørgen, Per Ekegren, Irmelin Gram-Hanssen, Pirjo Korpela, Nanna LangevadClifforth, Kristin Skov-Olsen, Kirsi Silvennoinen, Malin Stare, Åsa Stenmarck, and Erik Svanes. 2016. "Food Redistribution in the Nordic Region." TemaNord 502. Copenhagen. doi:10.6027/TN2014-562.

Holm, Lotte, Marianne Pipping Ekström, Jukka Gronow, Unni Kjærnes, Thomas Bøker Lund, Johanna Mäkelä, and Mari Niva. 2012. "The Modernisation of Nordic Eating." Anthropology of Food (S7): 1-11. http://aof.revues.org/6997.

Holm, Lotte, Thomas Bøker Lund, and Mari Niva. 2015. "Eating Practices and Diet Quality: A Population Study of Four Nordic Countries.” European Journal of Clinical Nutrition 69 (7): 791-798. doi:10.1038/ejcn.2015.61.

Jastran, Margaret M., Carole A. Bisogni, Jeffery Sobal, Christine Blake, and Carol M. Devine. 2009. "Eating Routines. Embedded, Value Based, Modifiable, and Reflective." Appetite 52 (1): 127-136. doi:10.1016/j.appet.2008.09.003. 
Johnston, J., M. Szabo, and a. Rodney. 2011. "Good Food, Good People: Understanding the Cultural Repertoire of Ethical Eating." Journal of Consumer Culture 11 (3): 293-318. doi:10.1177/1469540511417996.

Jonsson, Hans, Lena Borell, and Gaynor Sadlo. 2000. "Retirement: An Occupational Transition with Consequences for Temporality, Balance and Meaning of Occupations." Journal of Occupational Science 7 (1): 29-37. doi:10.1080/14427591.2000.9686462.

Kahma, Nina, Johanna Mäkelä, Mari Niva, and Thomas Bøker Lund. 2014. "Associations between Meal Complexity and Social Context in Four Nordic Countries." Anthropology of Food S10: 1-22. http://aof.revues.org/7666.

Kjærnes, Unni, Marianne P. Ekström, Jukka Gronow, Lotte Holm, and Johanna Mäkelä. 2001. "Eating Patterns. A Day in the Lives of Nordic Peoples." In Eating Patterns. A Day in the Lives of Nordic Peoples, edited by Unni Kjærnes, 25-64. Lysaker, Norway: National Institute for Consumer Research.

Kristensen, Søren Tange, and Lotte Holm. 2006. "Modern Meal Patterns: Tensions Between Bodily Needs and the Organization of Time and Space." Food and Foodways 14 (3-4): 151173. doi:10.1080/07409710600962316.

Laakso, Senja. forthcoming. "Giving up cars - the impact of a sustainable mobility experiment on carbon emissions and everyday routines" Journal of Cleaner Production.

Laakso, Senja, Annukka Berg, and Mikko Annala. forthcoming. "Dynamics of experimental governance. A meta-study of functions and uses of climate governance experiments" Journal of Cleaner Production.

Laakso, Senja, and Michael Lettenmeier. 2016. "Household-Level Transition Methodology towards Sustainable Material Footprints." Journal of Cleaner Production 132. Elsevier Ltd: 184-91. doi:10.1016/j.jclepro.2015.03.009.

Lee, Siew-peng. 2015. "Eating Solo: Food Practices of Older Hong Kong Chinese Migrants in England." Food and Foodways 23 (3): 210-230. doi:10.1080/07409710.2015.1066224.

Leray, Loïc, Marlyne Sahakian, and Suren Erkman. 2016. "Understanding Household Food Metabolism: Relating Micro-Level Material Flow Analysis to Consumption Practices." Journal of Cleaner Production 125: 44-55. doi:10.1016/j.jclepro.2016.03.055.

Maguire, Jennifer Smith. 2016. "Introduction: Looking at Food Practices and Taste across the Class Divide." Food, Culture \& Society 19 (1): 11-18. doi:10.1080/15528014.2016.1144995.

Mattinen, Maija, Riina Antikainen, and Marja Salo. 2014. "Jyväskylän Resurssiviisaiden Kokeilujen Vaikutusarviointi Sekä Laajenemisvaikutukset.” Sitran Selvityksiä 75. Helsinki.

Ministry of Agriculture and Forestry (MAF). 2014. "Maatalouden Ilmasto-Ohjelma Askeleita Kohti Ilmastoystävällistä Ruokaa." Publications of the Ministry of Agriculture and Forestry 8. Helsinki. doi:10.1016/B978-84-9022-505-9/oooo8-X. 
Mäkelä, Johanna, Unni Kjærnes, Marianne Pipping Ekström, Elisabeth L'orange Fürst, Jukka Gronow, and Lotte Holm. 1999. "Nordic Meals: Methodological Notes on a Comparative Survey.” Appetite 32: 73-79. doi:10.1006/appe.1998.0198.

Nielsen, Annemette, and Lotte Holm. 2016. "Making the Most of Less." Food, Culture \& Society 19 (1): 71-91. doi:10.1080/15528014.2016.1145003.

Paddock, Jessica. 2015. "Household Consumption and Environmental Change: Rethinking the Policy Problem through Narratives of Food Practice." Journal of Consumer Culture. doi:10.1177/1469540515586869.

Pliner, P., and R. Bell. 2009. "A Table for One: The Pain and Pleasure of Eating Alone." In Meals in Science and Practice: Interdisciplinary Research and Business Applications, edited by Herbert L. Meiselman, 169-189. Cambridge: Woodhead Publishing Ltd.

Polivy, Janet, and Patricia Pliner. 2015. "'She Got More than Me'. Social Comparison and the Social Context of Eating.” Appetite 86: 88-95. doi:10.1016/j.appet.2014.08.007.

Porpino, Gustavo, Juracy Parente, and Brian Wansink. 2015. "Food Waste Paradox: Antecedents of Food Disposal in Low Income Households." International Journal of Consumer Studies 39 (6): 619-629. doi:10.1111/ijcs.12207.

Reckwitz, Andreas. 2002. "Toward a Theory of Social Practices: A Development in Culturalist Theorizing." European Journal of Social Theory 5 (2): 243-263. doi:10.1177/13684310222225432.

Reisch, Lucia A., Ulrike Eberle, and Sylvia Lorek. 2013. "Sustainable Food Consumption: An Overview of Contemporary Issues and Policies." Sustainability: Science, Practice, \& Policy 9 (2): 7-25.

Rotenberg, R. 1981. "The Impact of Industrialization on Meal Patterns in Vienna, Austria." Ecology of Food and Nutrition 11: 25-35. doi:10.1080/03670244.1981.9990653.

Schatzki, Theodore R. 2002. The Site of the Social: A Philosophical Account of the Constitution of Social Life and Change. The Pennsylvania State University Press.

Shove, Elizabeth, and Alan Warde. 2002. "Inconspicuous Consumption: The Sociology of Consumption, Lifestyles, and the Environment." In Sociological Theory and the Environment. Classical Foundations, Contemporary Insights, edited by Riley E. Dunlap, Frederick H. Buttel, Peter Dickens, and August Gijswijt, 230-251. Oxford: Rowman \& Littlefield Publishers, Inc.

Silvennoinen, Kirsi, Juha Matti Katajajuuri, H. Hartikainen, Lotta Jalkanen, Heta-Kaisa Koivupuro, and Anu Reinikainen. 2012. "Food Waste Volume and Composition in the Finnish Supply Chain: Special Focus on Food Service Sector." Fourth International Symposium on Energy from Biomass and Waste (November 2012): 14.

Sobal, Jeffery, and Mary K. Nelson. 2003. "Commensal Eating Patterns: A Community Study.” Appetite 41 (2): 181-19o. doi:10.1016/So195-6663(03)ooo78-3. 
Southerton, Dale. 2013. "Habits, Routines and Temporalities of Consumption: From Individual Behaviours to the Reproduction of Everyday Practices." Time \& Society 22 (3): 335-355. doi:10.1177/0961463X12464228.

Tukker, Arnold, Maurie J. Cohen, Klaus Hubacek, and Oksana Mont. 2010. "The Impacts of Household Consumption and Options for Change." Journal of Industrial Ecology 14 (1): 13-30. doi:10.1111/j.1530-9290.2009.00208.x.

van't Riet, Jonathan, Siet J. Sijtsema, Hans Dagevos, and Gert Jan de Bruijn. 2011. "The Importance of Habits in Eating Behaviour. An Overview and Recommendations for Future Research." Appetite 57 (3): 585-596. doi:10.1016/j.appet.2011.07.010.

Warde, Alan. 1999. "Convenience Food: Space and Timing." British Food Journal 101: 518527. doi:10.1108/00070709910279018.

Warde, Alan. 2005. "Consumption and Theories of Practice." Journal of Consumer Culture 5 (2): 131-153. doi:10.1177/1469540505053090.

Warde, Alan. 2016. The Practice of Eating. Cambridge: Polity.

Warde, Alan, Shu-Li Cheng, Wendy Olsen, and Dale Southerton. 2007. "Changes in the Practice of Eating: A Comparative Analysis of Time-Use." Acta Sociologica 50 (4): 363-385. doi:10.1177/0001699307083978.

Watson, Matt, and Angela Meah. 2012. "Food, Waste And Safety: Negotiating Conflicting Social Anxieties Into The Practices Of Domestic Provisioning." Sociological Review 60 (S2): 102-120. doi:10.1111/1467-954X.12040.

Videira, Nuno, Frieder Rubik, Michael Sedlacko, Paula Antunes, Rui Santos, and Ria Müller. 2013. "Shaping the Future of Sustainable Food Consumption: Challenges and Opportunities for Policy and Science Integration." Paper presented at the 2nd Multinational Knowledge Brokerage Event on Sustainable Food, Lisbon, April 18-19.

Yates, Luke, and Alan Warde. Forthcoming. "Eating Together and Eating Alone: Meal Arrangements in British Households." British Journal of Sociology. Advance online publication. 